\section{Deep Community: Phenomenology's Disclosure of the Common Good}

\author{
H. Peter Steeves \\ Indiana University
}

Editors' Note: This paper by Professor Steeves was presented at the Eastern Division meetings of the Society for the Study of Ethics and Animals, held in Boston, MA, December, 1994. A response by Carlton Dallery was unavailable at the time this issue went to the printer, and will be published at such time as it is available.

\section{Introduction: The Circle of Life}

There is something intriguing about the opening scene of the Walt Disney movie "The Lion King." It is not just that the animals are all speaking and singingthough the fact that nearly every Disney movie and so many other shared stories and fables include animals who have the ability to communicate their thoughts with us must tell us something about the human psyche in general. It is, rather, what the animals are singing. Mufasa, the current lion king, has a new son named Simba, and all of the animals of the jungle and the plains are gathering so that Simba can be introduced to them in a customarily regal way. The animals sing about the "circle of life," and they fall to their knees when the new lion cub-the cub who will be king-is finally presented to them, held aloft on a rock precipice overlooking the kingdom.

Now, "The Lion King" has been accused of a lawyer's-list of political correctness violations. It is, supposedly, sexist because it focuses on the life of male power-players: it is racist because the voices of the nasty characters are done by minorities; it is

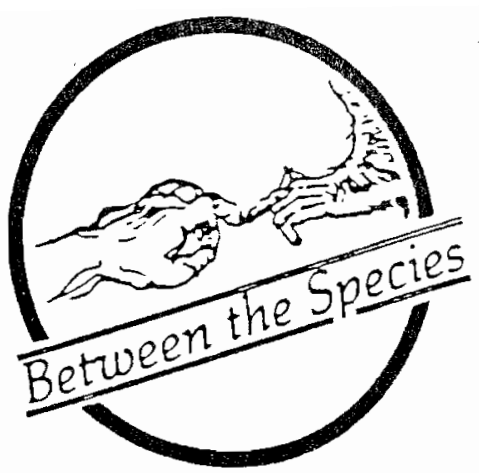

homophobic because the evil lion is drawn and voiced "effeminately"; and it is classist because it is, once again, a story of the comings and goings of royalty, life in the upper bourgeoisie-as if nothing of interest could happen to a lowly member of the proletariat or to someone lower on the food chain; as if no one would care to see a movie entitled "The Lion Peasant" or "The Slug King."

Whether or not we agree with such criticisms, once voiced they inevitably affect our experience of the movie in retrospect. The point I wish to bring up, though, is not so much a criticism as it is a bit of confusion. I was confused during "The Lion King" because I could not understand why all of these animals were so happy that another lion had been born. After all, it won't be long until Simba is hunting, killing, and eating most of these creatures who are attending his presentation party with such joy.

Some explanation is given a few minutes into the film when Mufasa is showing Simba around the jungle and explaining this "circle of life" of which everyone was singing earlier. He tells Simba that even though the lions eat the antelope, for instance, one day the lions will die and their bodies will decay, which will fertilize the grass so that the next generation of antelope will have something to eat. Everybody helps everybody else in the circle of life-it is a balanced community of cooperative eating and being eaten.

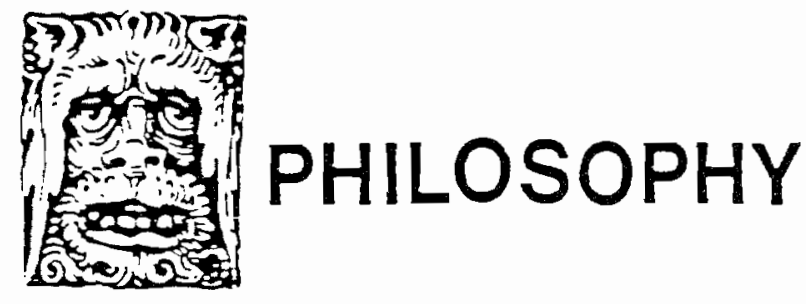


At this point, I am afraid that 1 find myself in agreement with Terrence Rafferty, film critic for the New Yorker, who remarks that Mufasa's claim " "We're all connected' [through the eating chain is]...easy for him to say; it seems unlikely that the antelopes share this philosophical serenity."1 Indeed, one wonders if the antelope consider this "circle of life" to be a community at all; no doubt they would tell a different story if they had the power of the narrative pen.

But this raises many important and interesting questions. Is there such a thing as an animal community, and if so, how are its members determined? How is this community created and does it include humans? Disney, of course, is just one instance of humanity's tendency to anthropomorphize animals. In such stories we tend to see projections of ourselves, and surely in "The Lion King," the lions are "the humans of the jungle." They have the power to speak for the rest, and upon closer inspection Mufasa's speech about the "circle of life" sounds very human, echoing the same attitudes and philosophies which keep modern society content with the institutions of pets, zoos, factory farming and all of our carnivorous and exploitative traditions in general.

Human communities and a human communitarian ethic have existed for sometime. The former have been studied and the latter have been debated extensively. But little attention has been given to a deeper sense of community-a community without species boundaries-and to the ethic which might result. I would like to propose that community is not limited to human members. Communal membership and, consequently, communitarian moral status extend beyond the seemingly arbitrary boundaries of our human societies and collectivities. My goal is to suggest how this is so from the particular vantage point of continental philosophy and, more specifically, phenomenology-a discipline which has much to say on the subject.

\section{Possible Paths Toward Community: Animal Phenomenology}

There are several ways in which animal membership in a communitarian ethic can be established. ${ }^{2}$ The first uses community in a somewhat loose way and seeks to demonstrate that animals are individuals-that they count as moral beings--and thus they are to be considered members of the community of persons.
Phenomenology's role in such an endeavor is, actually, quite important. The traditional problem has been that animals ${ }^{3}$ seem incapable of possessing goods and reflecting on their actions. To take a typical and often quoted example, consider Aquinas' discussion of irrational creatures:

Strictly speaking we cannot will goods to irrational creatures because they cannot "have" goods in the proper sense of the word ...[J]udgement is the power of one judging insofar as he can judge about his own judgement....But to judge about one's own judgement belongs only to reason which reflects upon its own act.... Hence, the whole root of freedom is located in reason. ${ }^{4}$

To this, Peter Drum adds the following interpretation. Aquinas, he argues, is suggesting that

irrational creatures are not proper goodpossessors... [because] they are not proper beneficiaries of other-regarding acts....The point is that only rational beings are capable of reflective awareness or self-consciousness: They can be aware of being aware, i.e., aware of their own beliefs, thoughts and judgements. ${ }^{5}$

It is helpful here to shift the focus of this inquiry from questions concerning rationality-a loaded-term often irrationally tossed about - to questions of intentionality. After all, the problem seems to focusfor Aquinas and many others-on an animal's ability for reflective awareness, the state of being aware of being aware. In other words, animals are often left out of the moral community of persons because it is assumed that they have no phenomenological life-or at least one to which we do not have access.

But is this fair? Initially, it seems straightforwardly impossible to posit animal phenomenology, for the whole idea of phenomenological analysis is that the phenomenologist has access to his or her own consciousness and experience and therefore has a special and secure knowledge. I might not actually be in my office right now as I write these words. I might be hallucinating, tricked, or a brain in a vat, but there is one thing of which I am sure: I am having the experience of being in my office. It is a bit of secure knowledge like no other. And by studying the structures of such 
experiences we can come to uncover the structures of consciousness itself-the interplay of presence and absence, the various modes of presentation of objects, etc. The problem is that making claims about animal experience seems to overstep the boundaries of phenomenology. The practicing phenomenologist does not have access to the experience of the animal and thus cannot make claims as to its structure.

This is mistaken for a variety of reasons, not the least of which is human arrogance and hubris. Why is it that Husserl (or any other phenomenologist) would think that phenomenology is valid for anyone but themselves? That is, since I do not have access to the consciousness of a Frenchman, why would I think that I have the right to speak about structures of consciousness in Frenclumen? Naturally, because I must assume a basic similarity between my own experience and the experience of the Other. Nationality, race, class, and .gender all surely affect one's horizon of experience, yet the basic, generic structures of consciousness itself must be assumed as a constant. But why stop here? Why not allow species to be one characteristic of an individual that affects the shape of her experience but not the basic structure of that experience? The problem is that we cannot have our cake and eat it too. If we do not include animals in our phenomenology then we should not include any Others. To put it another way, in what sense do we not have access to animal experience? One could argue that our experience is fundamentally the experience of a living being, the experience of an animal, and then the experience of a human. Our humanity filters our world and alters our horizon of possible experience, but it does not dictate an exclusive structure to consciousness.

Yet, even if we assume that we do not have direct access to animal consciousness and thus cannot speak properly of animal phenomenology, it is possible that such a phenomenology could be reconstructed. Husserl never published on the notion of reconstructive phenomenology in his lifetime, but the Nachlass texts have scattered references. ${ }^{6}$ Here, Husserl suggests reconstructing what the intentional life of a human infant must look like. The practicing phenomenologist has no access to infantile consciousness - to burgeoning human intentionality in its most early stages-but Husserl suggests that we can reconstruct the structures of such a wakeful life.

A similar story, then, could be told of animals. Observing animal behavior we are quick to posit such structures as identity synthesis, the experience of multi-sensory unities, presence and absence, etc. The cat who waits for the mouse to re-emerge from the hole in the floorboard seems to be presencing the mouse as absent. The mouse was here before (presenced as present) but he is not here now (presenced as absent). If the mouse were not being presenced as absent, the cat, we imagine, would not be waiting and staring so intensely. Furthermore, the dog who hears a noise and rushes to the door to growl at the mailman seems to be experiencing the world as made up of multi-sensory unities. The creak of the mailbox lid being opened, footfalls on the porch, etc. are auditory aspects related to a rich multi-sensory unity - a unity for which the dog expects to have visual confirmation when he rushes to the door. The mailman, we conclude, is a unified collection of sounds and images and smells, etc.

These are relatively important accomplishments, and there seems to be no reason to refuse to believe that most animals are in possession of rich intentional lives and thus have the right to be thought of as individualspersons-within the moral community.

\section{Community through Commonality}

But this is a community only in a libertarian and, I would suggest, improper sense. A community, one might argue, is not a collection of isolated monadic individuals but, rather, a union of interrelated group-members bound together by commonalties. If we work with this notion of community, is it possible to argue that nonhuman animal life can still claim membership? What, in fact, do we have in common with animals that might lead to the establishment of a community?

The first and most obvious answer to this question is that we share a common world and thus a common future with animals. This is no startling claim. Our interconnection with animals and the living world is, in some sense, commonsensical, though it tends to be obscured by our contemporary lifestyle-a way of being-in-the-world such that our relatedness is "suppressed." 8 Hamburger does not come from a grocery and spotted owls do not exist to play the role of political pawns, no matter the degree to which the world inight appear so.

A common critique of such communitarian foundations, though, is that we tend to include animals in the community only to the degree to which they are 
important to and otherwise affect us. That is, animals are added to our community as we grow to realize their importance to human existence. Such an anthropocentric ethic does not sit well with deep ecologists such as Dave Foreman, co-founder of Earth First!. Foreman rejects such notions as "a huge failure of moral imagination" and argues that "[a]ll living things have intrinsic value, inherent worth.... They live for themselves, for their own sakes, regardless of any real or imagined value to human civilization."

But there are many examples of non-anthropocentric theories based on human and animal interconnections. Some Native American world-views are excellent examples of such theory and practice. John Mohawk's important work in providing a communitarian reading of the Iroquois Confederacy's oral tradition suggests that the Six Iroquois Nations lived by a "deep ecological" or "deep communal" rule where humans are said to be in community with animals, plants, rivers, air, etc. The laws of justice established by the Six Nations covered not only the human citizens but the other members of the community as well. Such a form of communitarianism-a lived theory with a long history before it was forcibly eradicated by physically destroying its practitioners - is well worth greater study. ${ }^{10}$

And there are other approaches to community through commonality. Alphonso Lingis' recent work suggests that there is a "Community in Death" of which humans and animals are members in virtue of the fact that we are all mortal. ${ }^{11}$ This is intriguing because species kinship plays no role in Lingis' view of cominunity - the Other, human or animal, shares a connection to me when I put myself "wholly in the place of the death that gapes open" for her. ${ }^{12}$

Death, though, is only part of the story of our lives, and perhaps it is the case that we share more of this story-more than the final death scene-with animals. Building a community on the foundation of a shared story or the on-going process of narrative creation is another communitarian tradition with a rich history. Stanley Hauerwas, Alasdair MacIntyre, and David Carr have written in this area, though none lnas dealt extensively with the specific topic at hand-that of determining the role of nonhuman animal life in the creation of the stories which "inflate us to life" and provide us with meaning.

Carr, for instance, has some insight into the role of narrative in human communities. He suggests that [a]t whatever level or size or degree of complexity, a community exists wherever a narrative account exists of a we which has continuous existence through its experiences and activities. When we say that such an account "exists," we mean to say that it gets articulated or formulated, perhaps by only one or a few of the group's members, in terms of the we and is accepted or subscribed to by the other members. It is their acceptance that makes them members, [and] constitutes their recognition of the others as fellow members.... To be a participant or member in this sense, and to posit a we as group-subject of such a communal story, are really the same thing. ${ }^{13}$

One of the problems with such an account is that it fails to recognize the power of the story-teller and thus the possibility that certain characters in the communal story are marginalized — even written-out. Carr suggests that one's acceptance of the narrative makes one a member of the "we." The point, at first, seems to be well taken. I am quite sure that when the Ku Klux Klan rallies under slogans such as "We believe in a white America," the we fails to refer to me because I do not accept a role in that narrative- the Ku Klux Klan story is not my story. ${ }^{14}$ And the point can be made in less extreme situations as well. When Native Americans or Scandinavians or Buddhists speak of a "we" and tell a story which is "ours," I know that the "we" does not include me-these stories and thus these communities are not mine.

But this is too simplistic. It is an inaccurate view of the way narrative operates, because it takes for granted the fact that I am free to choose the story in which I am enmeshed. But is this so? If I hear someone say, "We have become obsessed with O. J. Simpson," or if President Clinton goes on television and declares "We will not lift the Cuban embargo," in what sense am I free to say that these "we" 's do not include me? Whether or not I agree with the Cuban embargo, am I not a part of the story through my action and even inaction-does this narrative not encompass me, with or without my consent? Indeed, if Carr is correct, such stories not only include me, they constitute me. I am what I am in virtue of the "we" of the narratives in which I find myself enmeshed. To assume otherwise is to posit an initial state where humans are isolated individuals, picking and choosing the narratives and thus communities in 
which they wish to participate--a fundamentally noncommunitarian assumption of what it is to be human. Consequently, communities, we must conclude, are not always constituted through consent.

This point becomes especially clear when we consider the role of animals in narrative. Clearly, animals are part of "our" story. What we do affects them; what they do affects us. In fact, this us/them distinction is fundamentally misdirected, since the narrative is common: humans and animals strut and fret, acting out their parts in a common space, within a common story. The difference is that animals do not seem capable of validating the narrative which humans construct for them. Recounting our history and preparing for our future, we tell the stories of where we have been and where we are going. We have spread across the earth and cut trails through the land. We have thinned the forests, and lawn-and-gardened the soil, blackened the skies and spiked the water. We have domesticated the tasty animals and attempted to eradicate the pests. We have fought one another and loved one another, and we hope to go on telling our story for many more years.

But do we have this right? When we say, "Our Hoover dam is a great dam-it would be best for us to build some more," who are "we"? "We" certainly must include the varieties of nonhuman animal life caught up in the story. "We," in some sense, refers to this life, but there is something improper about this reference because it is always and only uttered by humans. The "we" of such statements picks out human and animal alike, but there is something inauthentic about the way it does so to animals. Inevitably, we humans represent animals in the common tale we construct, but we do it willy-nilly. ${ }^{15}$

Is there any way around this, though? How can we consider and represent animal perspectives when we cannot hear animal voices? Some Deep Ecologists would claim that this approach is misdirected from the start because we have favored human stories and overlooked the fact that the story we tell is one of many concurrent tales, none more important than the rest in the non-hierarchical structure of nature. Perhaps, it all comes down to power-which the narrator has absolutely. The story-teller casts the parts, sets the scenes, and interprets the plothines, and those unnamed characters to which the "we" emptily refers have no say in the matter-unless they rip the pen from the storyteller's hand and write their own account.
If we are to say, though, that there is a right to revolution in narrative, and if we are to maintain that "we" can be used improperly-that it has been used improperly when we speak for the human and animal community without allowing the voices of animals to be heard and the goods of animals to be voiced-we are left with a difficult situation. If the "we" refers emptily, then we must assume that there is some more appropriate "we"-some more proper community than the one which the narrative "we" picks out and, supposedly, creates. In other words, if the narrative "we" constitutes the community, how can it ever be wrong? To what standard could we appeal when we offer our critique?

\section{Phenomenology and Deep Community}

Here is where the true force of phenomenology's response is to be felt, for there is a more foundational level of community than that which is brought into being through narrative-there is a more basic "we" which can be disclosed through phenomenological analysis.

In Husserl's Fifth Cartesian Meditation, he suggests that I never experience myself as an isolated, monadic individual but, rather, as a self among Others. In fact, the Ego and the Other are constituted in unison and in conjunction with the network of Others which forms my community. As the Ego arises in sense, so does the Other, and this fundamental presence of the Other founds my experience of the world as public. Such phenomenological truths become evident, Husserl maintains, when we attempt to perform a "reduction to a sphere of ownness." "As regards methods," he explains,

a prime requirement for proceeding correctly here is that first of all we carry out, inside the universal transcendental sphere, a peculiar kind of epoché... [where] we disregard all constitutional effects of intentionality relating immediately or mediately to other subjectivity and delimit first of all the total nexus of that actual and potential intentionality in which the ego constitutes within himself a peculiar owness. [sic]...But here something remarkable strikes us:...The psychic life of my Ego ...including my whole world-experiencing life and therefore including my actual and possible experience of what is other, is wholly 
unaffected by screening off what is other...I, the reduced "human Ego"... am constituted, accordingly, as a meinber of the "world"...16

In other words, if we attempt to strip the layers of experience until we arrive at a foundational level where the experience does not rely on the presence of what is alien or other (i.e., we uncover the sphere of ownness), we discover that the project is an immediate failure. Even the most basic experience of my own Ego is dependent on the Other; we necessarily live in an intersubjective world.

Now, what if we alter this argument in an attempt to uncover the point at which animals make their appearance in our experience? That is, we would attempt "a reduction to a sphere of human-ownness"stripping away any experience of what is nonhuman in an effort to uncover some foundational level of experience which does not include the experience of nonhuman animal life and is in no way dependent on such life for its meaning.

Attempting such a reduction we are once again struck by something remarkable. Even at the most fundamental level of experience, we find the presence of the animal-Other. The world, that is, is experienced as a common world - a world in which the human and the nonhuman animal necessarily acknowledge a mutual publicity. We cannot screen off or strip away the animalOther, for it would mean stripping away our own humanity and even our ability-the possibility of our ability-to have experience.

In many ways, this phenomenological fact is born out by empirical evidence as well. Mary Midgley speaks of a "well-filled stage," populated by members of "the mixed community," and maintains that "[a]Il human communities have involved animals." anthropological/sociological evidence cannot count as phenomenological proof, but it is consistent with our phenomenological findings. Thus, when Kenneth Shapiro claims, in the editor's introduction to the first issue of Society and Animals, that there is a "pervasiveness" of animals in our life and that "our world is...replete with animals in the street, home, nursing home, consulting room, at the 'feeder,' in the city alley and city park,... on the farm, in the stream, in the wild," ${ }^{18}$ he speaks to the obvious truth of a communal world - the obvious historical-empirical fact that there is no such thing as a human community that is not in the midst of animals. ${ }^{19}$
To be members of a mixed community is to share a world, but more than this, it is to acknowledge that the appearing world is this shared world - a common world on which humans and animals have different perspectives. Intersubjective Goods, then, are one aspect of this public world. In the same way that I take the Hoover dam to be a public object-i.e., in the same way that I take my perspective here to be a perspective on the same object which you have a perspective on over there-so, too, are Goods necessarily public. What I take to be good from my perspective, you can take to be good or bad from yours. The same action that a human considers good is good or bad from an animal perspective as well.

This is a strong claim. It amounts to more than saying that what we do affects each other, animals included. It is to say that our shared community is essentially soaked with morality. Robert Sokolowski has put the point succinctly:

We have no choice about adopting the moral point of view. We exist morally not by virtue of a decision, but by virtue of the fact that we share a world with other agents, and that what seems good to us will usually show up as good or bad to others, that as good or bad for others it can be good or bad for us, that there can consequently be both conflicts and harmonies in the intersection of goods and bads....[T]hat is the way we are... we are moral by the way we exist with others. ${ }^{20}$

Morality, then, is not a choice but a way of being in the world. Our good is tied up with the goods of those with whom we share the world; indeed, these goods are not actually separate goods but are perspectives on a common Good. It is phenomenologically impossible to suppress this publicity - to suppress our moral connection with the living world-though many of our actions and most past philosophical ethics do not begin with this proper foundation.

Our community is a deep one, and I would like to use this term, Deep Community, to refer to the collectivity uncovered and the common Goods disclosed through phenomenological analysis. The Deep Community is one in which animals claim full membership and animal goods stand at the same level as human goods. Many deep ecological claims are at home in such a theory, for animal status and worth is 
not dependent on an animal's usefulness to humanity or on our granting such status and worth to animals. Indeed, Deep Community "gets underneath" anthropomorphism, showing how such a mistake is possible and explaining the necessary preconditions and assumptions resting behind its faulty reasoning. Anthropomorphism is a privileging of the human perspective on the Good and it is fundamentally contradictory-both (a) in the sense that it must recognize the publicity of the common Good while at the same time characterizing this common Good as a human good and (b) in that anthropomorphic theories attempt to account for the presence of the animal-Other in terms that are wholly familiar and "of the Self."21

Deep Community, then, dictates a Deep Communitarianism. We can come to a better understanding of our duties and of who "we" are through the variety of ways I have been discussing. We learn more about each other - about the phenomenological life of animals, for instance-and we learn something about the way in which the Good appears from the perspective of the Other. We uncover what we have in common-a life, a death, and a destiny-and we tell our stories of commonality, our narratives which further define who "we" are, where we have been, and where the "circle of life"--now understood in its deep and rich sensewill lead us next.

\section{Notes}

1 Terrence Rafferty, "The Current Cinema," New Yorker, June 20, 1994, p. 88.

2 Established" is probably not the best word here. "Uncovered" or "disclosed" might be more accurate.

${ }^{3}$ I begin to use "animal" for "nonhuman animal" here for aesthetic reasons.

${ }^{4}$ Aquinas, Summa Theologica, IlIllae, 25, 3 (London: Blackfriars, 1963-75), and De Veritate, 24, 2 (Chicago: Regnery, 1952-54).

${ }^{5}$ Peter Drum, "Aquinas and the Moral Status of Animals," American Catholic Philosophical Quarterly vol. LXVI, no. 4. pp. 483-5.

${ }^{6}$ See, especially, Husserliana XV, pp. 608-610.

${ }^{7}$ Much more needs to be said here, but it goes beyond the scope of this essay. For more on the notion of animal phenomenology, one might consult my "The Boundaries of the Phenomenological Community: Non-Human Life and the
Extent of Our Moral Enmeshment" in Proceedings of the Second Conference on Persons, forthcoming 1995.

${ }^{8}$ The fact that relatedness cannot actually be suppressed will be a topic for us later.

${ }^{9}$ Steve Chase, ed. Defending the Earth: A Dialogue Between Murray Bookchin and Dave Foreman. (Boston: South End Press, 1991), pp. 115-16.

${ }^{10} \mathrm{Cf}$. John Mohawk's, "The Great Law of Peace," in Communitarianism: A New Public Ethics, Markate Daly, ed. (Belmont, CA: Wadsworth, 1994).

11 See Alphonso Lingis' The Community of Those Who Have Nothing in Common (Bloomington, IN: Indiana University Press, 1994). Though I am not in agreement with most of Lingis' claims here, his work on community is important and speaks to the relevance and importance of continental thought on this topic.

${ }^{12}$ Lingis (1994), p. 157.

${ }^{13}$ David Carr, Time, Narrative, and History (Bloomington, IN: Indiana University Press, 1986), p. 163.

${ }^{14}$ Indeed, I refuse to validate the view of the world inherent in that narrative.

15 One might consult James Hart's The Person and the Common Life (Dordrecht Kluwer, 1992), for more on this notion of an inauthentic "we." See, especially, pp. 264-74, 414-16, 458-62. Hart has worked out this theme in great detail, and much of what he has accomplished can be applied to the task at hand. Though animal "we" 's are not an explicit theme in The Person and the Common Life, the subject is touched on: "If we adopt the view that animals are monads, and therefore inherently entitled to respect we may not regard them as goods for humanity but as members of the monadic community, i.e., of the 'we' and 'us' to whom the world appears and for whom the goods are." (458)

${ }^{16}$ Edmund Husserl. Cartesian Meditations. Dorion Cairns, trans. (Dordrecht: Martinus Nijhoff, 1988), pp. 92-99.

${ }^{17}$ Mary Midgley, "The Mixed Community," The Animal Rights/Environmental Ethics Debate, Eugene C. Hargrove, ed. (Albany, NY: SUNY Press, 1992), p. 211.

${ }^{18}$ Kenneth Shapiro, "Editor's Introduction," Society and Animals vol. 1, no. 1, p. 1.

${ }^{19}$ Of course, there is the possibility that a "human community" might rise up without animals, but we would not want to call this a "buman community" in the same way that the term is used today. Just as there can be a feral childa child that never develops a full human ego because it is raised without the presence of the human-Other--so there 
can be a feral human community. Such a community would not possess the same qualities or identity as a fully human community (which is in the presence of the animalcommunity). For more on this, one might consult my "The Boundaries of the Phenomenological Community" and "The Familiar Other and Feral Selves" (work in progress).

${ }^{20}$ Robert Sokolowski, Pictures, Quotations, and Distinctions (Notre Dame, IN: Notre Dame Press, 1992), p. 256. Sokolowski does not extend this moral interconnection to animals because he does not see them as "moral agents."
We have already touched on this subject, though, and must maintain that there is no reason to limit the publicity of the world to human agents.

${ }^{21}$ i.e., such theories are phenomenologically contradictory in that they must presence the animal-Other as subject (this is the necessary precondition for having human experience; recall the reduction to a sphere of humanownness) and as object (capable of being objectified, defined, and used by the human subject).

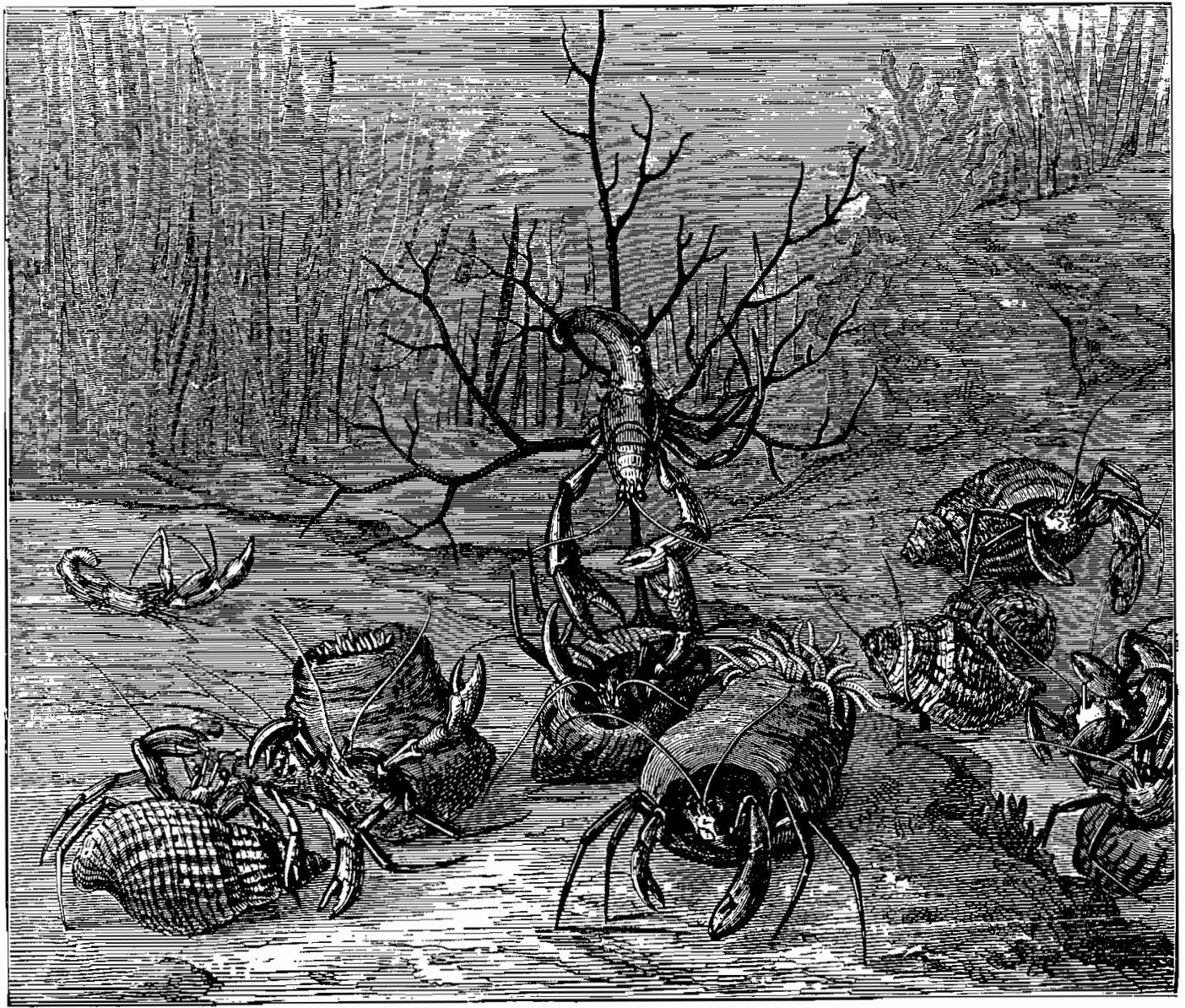

